\title{
ARGENTINA Y EL FMI. LAS MISIONES DE 2002 Y 2016 ENTRE LAS CRISIS RECURRENTES, EL PODER SIMBÓLICO Y LA GOBERNABILIDAD
}

\section{Germán Ezequiel Ricci*}

Investigador independiente

$\bowtie$ ger_ricci18@hotmail.com

\section{Horacio Divito**}

Universidad de Buenos Aires - Universidad de Ciencias Empresariales y Sociales

$\triangle$ horaciodivito@gmail.com
Recibido: 2 de febrero de 2021

Aceptado: 26 de mayo de 2021 DOI: 10.46553/colec.32.2.2021.p93-123

Resumen: Este artículo analiza la relación entre el Fondo Monetario Internacional y la Argentina a partir de las Misiones del año 2002 y 2016 desde el estructuralismo constructivista de Pierre Bourdieu. Se sostiene que el Fondo, en tanto instancia supraestatal que a su vez comparte el monopolio de la violencia simbólica con el Estado, otorga legitimidad a la elite local a partir de la rutina de la dependencia. Como máximo exponente del campo financiero, el FMI le concede a la elite gobernante el capital económico y simbólico necesario para sostener la gobernabilidad. De este modo, el Estado nación

* Licenciado en Sociología, Magister en Políticas Públicas por la Universidad de Sydney. Actualmente se desempeña como asistente de proyectos en OIM Argentina.

** Licenciado en Sociología, Magister en Investigación Social por la Facultad de Ciencias Sociales de la UBA. Docente en la Universidad de Buenos Aires y la Universidad de Ciencias Empresariales y Sociales. 
argentino, que atraviesa crisis económicas recurrentes, construye la base de la confianza del mercado financiero y de la comunidad internacional a partir de su relación con el FMI.

Palabras clave: Argentina, FMI, Poder simbólico, gobernabilidad, rutina de la dependencia

\begin{abstract}
This article analyzes the relationship between the International Monetary Fund and Argentina from the Missions of 2002 and 2016 from the constructivist structuralism of Pierre Bourdieu. It is argued that the Fund, as a supra-state body that in turn shares the monopoly of symbolic violence with the State, grants legitimacy to the local elite based on the routine of dependency. As the greatest exponent of the financial field, the IMF awards to the ruling elite the economic and symbolic capital necessary to sustain governance. In this way, the Argentine nation-state, which is going through recurring economic crises, builds the foundation of trust in the financial market and the international community based on its relationship with the IMF.
\end{abstract}

Keywords: Argentina, IMF, Symbolic power, governability, dependency routine

"Todos los caminos conducen al FMI", Remes Lenicov en febrero del 2002, por entonces ministro de economía argentino

\title{
I. Introducción
}

La relación entre el Fondo Monetario internacional (FMI) y la Argentina es tan larga como intensa. En 1956, nuestro país adhirió a los Acuerdos de Bretton Woods y tan solo dos años después solicitó su primer préstamo. Desde entonces, la participación del Organismo financiero en la economía argentina ha sido una constante, tanto como sus recurrentes crisis económicas. A los 29 acuerdos firmados en el periodo 1956-2006 (Nemiña 2013, 153), debe sumarse el reciente acuerdo sancionado en el año 2018, con su posterior modificación en octubre. A su vez, el Fondo ha participado 
activamente en el monitoreo de su actividad económica a través de sus Misiones.

Estas visitas oficiales responden al Artículo IV del Convenio Constitutivo del FMI, para cumplir con una de sus funciones principales, que consiste en supervisar el sistema monetario internacional a fin de asegurar su buen funcionamiento, y vigilar el cumplimiento por cada país miembro de sus obligaciones. Esto permite prevenir la inestabilidad financiera y económica (FMI 2011, 5-8). La vigilancia financiera de cada país es un proceso continuo que culmina en consultas integrales regulares (generalmente anuales) con los países miembros individuales, a través de las Misiones. Durante una consulta del Artículo IV, un equipo de economistas del FMI visita un país para evaluar la evolución económica y financiera y discutir sus políticas en esas materias con funcionarios del gobierno y del banco central.

Las Misiones del FMI en los países desarrollados con bajo endeudamiento tienen un carácter técnico y formal, de poca relevancia en el espacio público. Éstas producen un impacto moderado, tanto en los medios de comunicación como en el sistema político. No sucede lo mismo en los países emergentes endeudados (o con intenciones de endeudarse) como la Argentina, en los que la presencia y conclusiones del Fondo durante las Misiones generan una gran expectativa en los agentes financieros internacionales y locales.

Para el caso argentino, analizar las Misiones permite comprender la interacción, por fuera de los recurrentes Acuerdos que, a priori, resultan más atractivos ya que expresan un momento crítico de la economía. Las Misiones, en cambio, plantean una relación más estable y rutinaria, con dimensiones temporales y locales, y que casi siempre se yuxtaponen con los periodos de endeudamiento con el Fondo. En este contexto de simultaneidad entre Misiones y Acuerdos, los primeros ocupan un lugar secundario en la agenda pública por lo que tienden a presentar elementos menos decorosos sobre las expectativas con el país prestatario. Si bien los Acuerdos revisten una pulcritud técnica y se amparan en condicionalidades que podrían ser garantía de lo esperado y lo acordado, siempre dejan un margen para la arbitrariedad. La propia burocracia del Fondo con sus especificidades técnicas da lugar a la posibilidad de incumplir y "perdonar" los desajustes. En cambio, en estos períodos de endeudamiento, las Misiones parecen ser 
una actividad más modesta, menos protagónica y es ahí donde pueden visualizarse más claramente las intenciones del Fondo, en particular en lo que se refiere a sus demandas y condiciones bajo la fuerza de su poder simbólico ${ }^{1}$.

Por lo tanto, el objetivo de este artículo consiste en analizar la relación entre la Argentina y el FMI a través de las Misiones 2002-2006 y 20162018, considerando sus dimensiones políticas y simbólicas en el ámbito nacional e internacional. La selección de estos periodos tiene relevancia histórica: ambas se dan en el marco de las dos crisis más importantes del siglo XXI y probablemente de la historia económica argentina. Para el primer caso, el FMI monitoreó de modo constante la economía argentina hasta el año 2006, en el marco de un Acuerdo transitorio Stand-by posterior a la suspensión de otro acuerdo que se encontraba vigente en el año 2001. En el 2006, el gobierno argentino canceló la deuda junto con la aplicación del artículo IV del Fondo. Para el segundo caso, el Gobierno nacional accedió nuevamente a las Misiones del Fondo, que fue seguido de un nuevo Acuerdo Stand-by sancionado en junio de 2018 y extendido en septiembre de ese mismo año. El análisis propuesto permitirá conocer las disposiciones del Staff y de los miembros poderosos del Organismo en las negociaciones con Argentina, como también comprender su aporte a la gobernabilidad. Estudiar la relación entre el FMI y la Argentina partiendo de las Misiones que responden al Artículo IV del Convenio Constitutivo del Fondo como unidad de análisis, permitirá complementar los extensos trabajos académicos que generalmente se apoyan en los Acuerdos sancionados.

En particular, recurrimos a la teoría de los campos de Bourdieu, que constituye un enfoque teórico escasamente utilizado en las relaciones internacionales. Las conceptualizaciones en términos de legitimidad y poder simbólico de esta perspectiva resultan pertinentes para el objetivo de nuestro trabajo $\mathrm{y}$, además, permiten abordar una temática desde una perspectiva sociológica, con foco en la relación entre el Fondo y la elite gobernante.

1 Por poder simbólico, entendemos un conjunto de estrategias construidas socialmente en contextos de esquemas asimétricos de poder, que implican la imposición de una creencia de modo implícito. Es un poder invisible que no es reconocido como tal, y por lo tanto es percibido como legítimo. En este sentido, la presencia rutinaria internalizada que integra el aparato burocrático del Estado invisibiliza la relación de poder (Bourdieu y Passeron 2001). 
Para el desarrollo de este trabajo, recurriremos a fuentes periodísticas para recrear los acontecimientos sucedidos, relevando las manifestaciones públicas de los distintos agentes. Por otro lado, acudiremos a fuentes secundarias, esto es, investigaciones académicas de la época que hayan analizado aspectos de la relación entre el Fondo y Argentina. Por último, serán consideradas fuentes económicas oficiales que permitan contextualizar los mencionados períodos de nuestro análisis.

A partir del análisis de la relación entre Argentina y el FMI, se sostiene que el Fondo, en tanto institución prestamista cuya estructuración de poder responde a los intereses de los Estados miembros más poderosos, funciona además como un garante de gobernabilidad para el sistema político local en situaciones económicas críticas. Puede pensarse que, amparado en su poder simbólico, la relación con el Organismo le otorga al Estado legitimidad, en tanto su presencia es reconocida por los agentes financieros internacionales y nacionales, lo que evidencia y ratifica su posición dominante dentro de este campo. Como esta concesión de legitimidad es de carácter temporal, países con crisis recurrentes como la Argentina disponen de un crédito con fecha de vencimiento que posteriormente deberá ser revalidado. Atrapado en un inveterado proceso de endeudamiento, el Estado capitaliza momentáneamente el poder simbólico del Fondo, suficiente para alcanzar una tregua a mediano plazo. Los destinatarios de estos mensajes, es decir, el mercado financiero internacional (en el que también se incluye al propio Fondo), acceden a la concesión de esta tregua, que irá siendo parte de la reconfiguración de una nueva futura crisis económica. A su vez, el sistema político local capitaliza aquel poder simbólico en tanto garantiza un escenario político y económico gobernable. Este modelo de valorización financiera, que consiste en la toma de un crédito externo para postergar vencimientos de pagos, se superpone con los tradicionales ciclos argentinos de Stop and Go, en el que el propio sendero de crecimiento contribuye a la futura crisis (Bellini y Korol 2012; Rapoport 2008). El modelo exportador argentino basado en la producción de bienes primarios no solo históricamente produjo una limitada entrada de divisas para hacer frente a la balanza comercial y contribuir a los desequilibrios fiscales, sino que también se subordina a permanentes fluctuaciones de precios, lo que retroalimenta los ciclos de inestabilidad económica. 
En lo que sigue de este artículo, se explicita el marco teórico adoptado para el desarrollo de nuestro análisis. Posteriormente, se presenta la historia reciente de la relación entre Argentina y el FMI. Más adelante, se desarrollan las Misiones del Fondo en Argentina, de modo descriptivo y analítico. Finalmente, se presenta la conclusión, en la que se explicita el aporte del Fondo en términos de Gobernabilidad.

\section{Marco teórico}

Analizar la relación contemporánea entre Argentina y el FMI requiere posicionarse respecto a cuáles son las causas que explican el comportamiento del Organismo con los países prestatarios. Por un lado, algunos autores interpretan el accionar del Fondo como resultado de su burocracia institucional. En general, se trata de los constructivistas sociales (Nelson 2107; Park y Vetterlein 2010; Momani 2010; Chwieroth 2015) quienes consideran que las decisiones del FMI responden a la voluntad de su staff permanente. Estos autores, descreen de la influencia de los miembros más poderosos del FMI ya que consideran que su participación es meramente ocasional. A su vez, algunos ponderan la puesta en juego de la legitimidad del Fondo en cada intervención, lo que le daría autonomía de los Estados miembros más poderosos (Nelson 2017, 15). En este sentido, la agencia del Fondo responde a su cultura organizacional, independientemente de la estructuración de poder formal.

Del otro lado, están aquellos autores que consideran al Fondo como un brazo extendido del G7 (o, más precisamente, de Estados Unidos), que tienden a promover programas económicos según los intereses que tienen las potencias mundiales en esos países o regiones (Breen 2014; Kentikelenis y Babbs 2019; Stone 2008; Chapman et al. 2015; Edwards y Senger 2015). Esta perspectiva se ampara en la estructura decisional que tiene el Fondo, evidenciada por la asimétrica distribución de poder dentro del Organismo, en la que las potencias mundiales ocupan un lugar privilegiado. Si bien el Fondo fue reformado en el año 2010 con el objetivo de disuadir esta representación desigual, Estados Unidos aún mantiene su poder de veto ya que su sola abstención es suficiente para cancelar cualquier iniciativa que requiera una mayoría calificada. 
Desde nuestro punto de vista, el accionar del Fondo debe ser respondido por una perspectiva que se centre en las relaciones, en el posicionamiento de los actores y que permita captar las dimensiones simbólicas del Fondo, para lo cual, las mencionadas corrientes resultan ineficaces. Esto nos acerca a la Teoría de los Campos del estructuralismo constructivista impulsada por Pierre Bourdieu, un enfoque relacional que considera simultáneamente la estructura (parte objetivista, el campo) y la agencia (parte subjetivista, el habitus). Centra su análisis en el complejo entramado de relaciones entre actores y permite comprender sus acciones de acuerdo a la posición que ocupan en el campo social. De esta manera, Bourdieu se aleja del determinismo de otras perspectivas como el neorrealismo y, en todo caso, limita la subordinación de ciertos actores a determinado tiempo y espacio.

Desde la teoría de los campos, el FMI se encuentra posicionado dentro del campo financiero mundial que, liberado de todas las regulaciones, presenta una autonomía casi total (Bourdieu 2003). Considerando el posicionamiento del Fondo y su estructuración, lo entendemos como una organización prestamista que responde a los intereses de los Estados miembros más poderosos ${ }^{2}$. Su agencia, esto es, la búsqueda de la reproducción de su capital financiero, estará limitada por los intereses de los Estados miembros con mayor capacidad de decisión dentro del Organismo.

En este sentido, es de esperar que, si el Estado-nación prestatario en determinado momento histórico resulta relevante para las potencias con peso decisivo dentro del Fondo, el FMI representará más explícitamente los intereses de otro campo, del campo de la política internacional. Mientras

\footnotetext{
${ }^{2}$ Los Estados miembros más poderosos son aquellos que cuentan con un mayor poder decesión (mayor número de votos) dentro del Fondo. Esto se determina en gran medida por el tamaño de las cuotas, es decir, el aporte económico de cada Estado. Actualmente, Estados Unidos es el mayor contribuyente y la sola abstención de su voto es suficiente para cancelar cualquier iniciativa que involucre el consenso de una mayoría calificada (Blanchard et al. 2010). El G-7 (Estados Unidos, Japón, Alemania, Reino Unido, Francia, Italia y Canadá) concentra el $45 \%$ de votos. Las reformas iniciadas a partir del 2009 dentro del Fondo no fueron suficientes para disminuir la posición privilegiada de los Estados Unidos, su liderazgo y su poder de veto (Lesage et al. 2013). Además del poder formal, definido en cantidad de votos, debe considerarse el poder informal con el que cuentan las potencias mundiales para influenciar las decisiones de los otros países miembros.
} 
que, si no hay intereses geopolíticos de las potencias en ese país, en el Fondo primará una lógica inherente a la de una organización prestamista que busca maximizar sus beneficios financieros. En este marco se comprenden a los planes tradicionales de ajuste del gasto público que propone el Fondo como señales para el mercado del que el Estado es deudor. De tal modo, el Fondo no solo busca maximizar su capital financiero, sino también el del resto de los agentes de ese campo, al contribuir a que el Estado deudor destine sus recursos a sus compromisos externos.

En estos casos, el repliego de las potencias mundiales provoca una menor influencia de su campo sobre el financiero, lo que finalmente también constituye una decisión de las mismas. Para nuestro estudio de caso, Argentina resulta relevante para las potencias mundiales en contexto de crisis porque esto tiene efectos negativos sobre los intereses empresariales de origen extranjero, y además porque existen riesgos de que se genere un efecto dominó en el resto de la región (Kedar 2012).

En el campo internacional, las interacciones que se dan entre agentes financieros responden a la persecución y posesión de capital simbólico. Conocer por qué se lucha en este campo permite conocer qué está en juego en esas interacciones (Bourdieu, 1997). En su posición de acreedor que domina el campo financiero, varios autores han destacado que el Fondo es un prestamista de última instancia que opera como un garante económico para el resto de los acreedores privados (Nemiña 2011). Su presencia envía señales positivas o negativas al resto de los actores que interpretan que podrán cobrar su deuda a partir de una serie de reformas (políticas de ajuste) que el Fondo impondrá sobre el país prestatario. Esto implica que el Fondo no es solamente un agente preponderante en cuestiones de finanzas internacionales sino también que es una institución poseedora y proveedora de capital simbólico; el Fondo otorga algo más que un crédito, brinda legitimidad a una política gubernamental por la propia fuerza de su poder simbólico, a través del staff, o en última instancia, del directorio.

Respecto al poder simbólico del staff parece fundarse en una pseudo asepsia tecnocrática basada en la fuerza inapelable de una ciencia económica irrefutable. Sus recomendaciones o sus exigencias, según el caso, aparecen como decisiones administrativas meramente racionales, libradas de toda moral, característica que señalaba Max Weber de la dominación burocrática (2009). Generalmente, el staff, atrapado por su 
lógica burocrática, desconoce la fuente misma de su poder y que sus facultades van mucho más allá de las cuestiones técnicas. Cuando ocurren estos fallos o desajustes es cuando aparece en toda su dimensión la última instancia de la última instancia, el poder simbólico de los Estados, sean EEUU y/o el G7, expresados a través del Directorio.

En el campo nacional, la cotidianeidad del Estado Nación con el Fondo se materializa a través de los Acuerdos y las Misiones, que implican una interacción casi permanente. Esto genera lo que Kedar (2012) denomina la "rutina de la dependencia", que sirve para describir a aquellas actividades e interacciones entre el FMI y los funcionarios del país prestatario que permiten reafirmar al Fondo en la Argentina, relación que ha atravesado distintos tipos de gobiernos y partidos políticos. La relevancia del Fondo en el campo nacional se expresa en su razonable presencia cotidiana y física, en las que llegan al punto de ocupar despachos oficiales. Las Misiones aterrizan y se amparan en una lógica impoluta del saber tecnocrático, libre de valores, aunque a veces deslizan recomendaciones de tono ético ("Argentina debe ayudarse a sí misma" como afirmaban Kohler ${ }^{3}$ y Singh $^{4}$ en el 2002). Esto desnuda el poder simbólico del Fondo que implica una legitimidad naturalizada, capaz de ejercer violencia invisible inherente a su reconocimiento.

Tanto en el campo nacional como en el internacional, el Fondo es reconocido como el actor predominante en situaciones económicas críticas. Al operar como un banco central, en tanto prestamista económico y de poder simbólico, el FMI funciona como garante de última instancia cuando la legitimidad es difusa y la gobernabilidad frágil. En este sentido, el aporte del Fondo consiste en otorgar gobernabilidad, entendida como "un estado de equilibrio dinámico entre el nivel de las demandas societales y la capacidad del sistema político para responderlas de manera legítima y eficaz" (Camou 2000, 186) .

\footnotetext{
${ }^{3}$ Ex Director Gerente y Presidente del Directorio del FMI entre el 2000 y 2004.

${ }^{4}$ Lideró las Misiones a la Argentina a finales de los 90 y principios de los 2000 y fue responsable del Departamento del Hemisferio Occidental entre 2002 y 2008.

${ }^{5}$ Por demandas societales incluimos a aquellos actores dentro del campo nacional pero también a aquellos que participan dentro del campo internacional, como los agentes financieros globales.
} 
En este sentido, la presencia del Fondo, en tanto poseedor de capital simbólico, otorga estabilidad al sistema político local ya que contribuye al fortalecimiento del equilibrio del estado de la relación entre las demandas societales y la capacidad política. De este modo, la posición del Fondo como instancia supraestatal con respecto al gobierno (aunque infra estatal con respecto al G7) a su vez comparte el monopolio de la violencia simbólica con el Estado. Esta, fruto de la invisibilización que se logra a partir de la rutina de la dependencia, es entendida como una violencia que arranca sumisiones que ni siquiera se perciben como tales, transformando las relaciones de dominación y de sumisión en relaciones legitimas (Bourdieu y Passeron 2001).

Por lo tanto, solo de manera conjunta el Estado Nación y el Fondo son reconocidos en el campo nacional e internacional como agentes capaces de imponer y hacer cumplir las reglas de juego en el campo nacional para enfrentar una crisis económica, por fuera de la coerción/violencia física. De este modo, el Gobierno local logra acceder a la postergación de la crisis económica. Junto al Fondo pospone pagos para dilatar los ciclos de crisis recurrente y esto le otorga al Estado nacional gobernabilidad. Por lo tanto, los ciclos de crisis económicas recurrentes del gobierno argentino articulan la mayor o menor injerencia del Fondo en la política argentina.

\section{Historia reciente en la relación entre Argentina y el FMI}

La relación entre Argentina y el FMI comenzó hace más de 60 años y desde entonces ha sido algo dinámica pero permanente. Nuestro país fue el último de Latinoamérica en adherirse a los Acuerdos de Bretton Woods y establecer relaciones formales con el Fondo. Argentina había sido excluida en 1944, ya que se cuestionaba la falta de alineamiento político con Estados Unidos y su neutralidad en la Segunda Guerra Mundial (Kedar 2012). Sin embargo, 12 años después, Argentina adquirió la membresía del Fondo durante el gobierno de la Revolución Libertadora en 1956, pero para ello antes tuvo que reformar su estructura económica y modificar sus relaciones económicas internacionales (Giavedoni 2018). 
A tan solo dos años de ingresar, Argentina firmó su primer programa para estabilizar su economía en 1958 y desde entonces trabajó bajo la supervisión del Fondo durante 38 años casi ininterrumpidos.

Desde los 70, el FMI ha promovido en nuestro país programas neoliberales bajo la premisa de "ajustes estructurales" que cuestionaron el tamaño y las funciones del Estado. En cuanto a los resultados, los programas no han sido suficientes para corregir la balanza de pagos a corto y mediano plazo, y también han afectado negativamente el crecimiento económico, el empleo y la desigualdad a largo plazo (Brenta 2011). Durante estas décadas, el Fondo presionó tanto a la Argentina como a varios países de la región latinoamericana para la adopción de políticas propias del Consenso de Washington ${ }^{6}$. De hecho, particularmente durante los 90, el Fondo intensificó la promoción de determinados programas económicos vinculados a la dolarización de países emergentes. Esto ha sido publicitado en distintas conferencias y participaciones que ha tenido el Fondo a nivel mundial (Brenta 2004). Posteriormente, esta iniciativa fue desterrada a partir del nuevo siglo tras la crisis argentina de 2001 que mostró los límites del programa de la convertibilidad.

La injerencia del Fondo en los programas económicos nacionales no solo ha sido cuestionada por sus consecuencias socioeconómicas negativas, sino que también por los efectos en los sistemas democráticos, ya que las decisiones a nivel nacional no respondieron a la voluntad popular, sino que fueron guiadas por actores externos. En este sentido, algunos sostienen que

${ }^{6}$ El Consenso de Washington fue el conjunto de fórmulas económicas neoliberales impulsadas por varios organismos financieros internacionales para abordar la crisis económica de 1989 de Latinoamérica. Consistía en diez medidas económicas que profesaban el FMI, el Banco Mundial, el Banco Interamericano de Desarrollo y el Departamento del Tesoro de Estados Unidos, todas ellas con sede en la capital de Estados Unidos, Washington D. C. Este catálogo neoliberal recomendaba para la política económica interior minimizar el gasto público, los impuestos y las subvenciones, facilitar la inversión extranjera y local, favorecer a la empresa privada, desregular los precios y los despidos, y asegurar los derechos de propiedad privada, intelectual y de empresa. Para la política económica exterior, proponía liberalizar las importaciones y exportaciones, y orientar la moneda nacional hacia la competitividad internacional y la exportación no tradicional. Durante los años ochenta y noventa, los organismos financieros mundiales exigieron aplicar esas medidas para conceder créditos y ayuda financiera. 
fueron las grandes corporaciones y los bancos extranjeros en relación con los grupos financieros hegemónicos del capital trasnacional global los actores que guiaron el proyecto nacional (Martone 2004; Girón 2010).

Con respecto a la función que tuvo el FMI en Argentina, algunos autores sostienen que el Fondo ha sido históricamente un prestamista de última instancia. A partir de la crisis del 80, el Fondo fue un garante económico, en el sentido que su presencia les aseguraba a los acreedores privados el pago de la deuda. De este modo, el FMI se consolidó como un acreedor central para resguardar al sistema bancario internacional (Nemiña y Larralde 2018). A su vez, el FMI también funcionó como un catalizador de fondos privados ya que sus préstamos fueron bajos respecto al total de la deuda externa. Solo representaron entre el $4 \%$ y el $5 \%$ con solo picos del $7 \%$ y $9 \%$ en algunos pocos años (Brenta 2011). En este sentido, el sello de la organización ha facilitado el acceso a los mercados globales.

El análisis de la deuda externa Argentina da cuenta que los préstamos del Organismo no han sido suficientes para solucionar los problemas en esta materia. Las políticas financieras auspiciadas por el Fondo implicaron una serie de reformas económicas que no han disminuido la deuda total, sino todo lo contrario. El aumento de la deuda externa argentina presenta una pendiente ascendente a lo largo de los años que no se ha revertido con el paso de las décadas. Por ejemplo, durante la década del 70 que estuvo acompañada de varios acuerdos con el Fondo, la deuda externa se multiplicó por cinco (Girón 2006), mientras que, en los últimos años, ésta sigue en ascenso. Desde el 2010 al 2020, la deuda externa aumentó en un 90\%, pasando de \$144.653 millones de dólares a \$274.247 millones de dólares en marzo del 2020 (previo a la pandemia). Mientras que la deuda pública representaba el 38,5\% del PBI en 2011, pasó a representar el 90.2\% en 2019 y el 104,5\% en 2020, a solo dos años de un nuevo Acuerdo con el Fondo (INDEC 2020). En este sentido, cabe preguntarse, cuál es el aporte del Fondo hacia el país prestatario si sus programas no son útiles para solucionar los problemas económicos que lo convocan ni tampoco sirven para reducir sus deudas.

A partir de la década de los 90, la relación entre el Fondo y el gobierno argentino tomó una dinámica particular. Durante los primeros diez años, se desarrolló una estrecha relación entre los funcionarios argentinos y el staff del Organismo, que estuvo avalada por la alianza geopolítica entre 
Argentina y los Estados Unidos. La afinidad político económica entre ambos influyó en el tamaño, las condicionalidades y el cumplimiento de estas durante el acuerdo (Nelson 2017). Las creencias económicas neoliberales compartidas han determinado una estrategia cooperativa por parte del Fondo que ha sido clave para acceder a monitoreos laxos e incrementos en los préstamos, sobre todo en contexto de incertidumbres, esto fue cuando los resultados económicos se alejaban de las predicciones del Fondo.

Desde que comenzó el nuevo siglo, la estrategia cooperativa del Fondo con Argentina se diluyó. A partir de la pérdida de poder político del oficialismo a nivel nacional como consecuencia de los resultados legislativos electorales de 2001, la profundización de la crisis económica y el cambio del gobierno de Estados Unidos, hicieron que el Fondo adopte una estrategia confrontativa con Argentina. Durante el gobierno de la Alianza y con la administración precedida por Bush en Estados Unidos, el Fondo adoptó una supervisión firme que derivó naturalmente en la suspensión del acuerdo ya que los incumplimientos del Gobierno argentino se fueron reiterando. En ese entonces, el Fondo canceló la quinta revisión del acuerdo y el desembolso pautado para diciembre de ese mismo año (Nemiña 2011).

Con respecto al periodo que le sigue a la crisis económica, política, social e institucional posterior al 2001, varias investigaciones centradas en Latinoamérica han descripto el "alejamiento" del Fondo, no solo de la Argentina sino también del resto de la región latinoamericana, como respuesta a los resultados que habían tenido los países emergentes siguiendo la agenda neoliberal y las recetas del Consenso de Washington. Así, el FMI habría experimentado una crisis de "legitimidad" o "identidad" ya que se cuestionaban tanto sus recetas económicas neoliberales como su responsabilidad en las mencionadas crisis. Esto coincidió con el auge económico de varios países de la región cuya orientación políticoeconómica reivindicaba el rol del Estado (Jiménez y Lorenzo 2010; Martone 2004). Cabe mencionar que si bien el nivel de endeudamiento con el Fondo durante este periodo fue bajo, todos los Estados de la región reconocieron la legitimidad de sus deudas con el Organismo, cumplieron con el pago y mantuvieron la membresía con la entidad. 
A partir del año 2015, Argentina experimentó un progresivo acercamiento con el Fondo. Además de retomar las Misiones, nuestro país sancionó un acuerdo récord, el más grande jamás otorgado por la entidad (Cuattromo 2018). La acelerada fuga de capitales sumado a la dificultad para acceder a crédito privado provocó que en el año 2018 se sancionara un préstamo por $\$ 50.000$ millones de dólares, que luego fue extendido a \$57.000 millones de dólares.

El nuevo acuerdo trajo consigo las tradicionales premisas de ajuste fiscal para hacer frente al pago de la deuda. En ese sentido, varios autores sostienen que se trata de la vuelta del neoliberalismo a la Argentina (Bona 2019; Mussachio 2020). Otros en cambio, destacan la inclusión de gasto social para los sectores vulnerables como aspecto novedoso, a pesar de mantener la tradicional agenda del ajuste (Natanson 2019). De todas formas, el gasto social del acuerdo carece de condicionalidades, lo que revela el escaso compromiso con esta área, comprobando así la tradicional perspectiva del FMI (Bonavida et al. 2018).

Desde que se implementó el acuerdo y se desató la pandemia producto del COVID-19, el FMI ha apoyado hasta el momento la estrategia confrontativa del gobierno argentino frente a los acreedores privados. Esto podría responder a que el FMI está actualmente condicionado por Argentina ya que uno de cada dos dólares prestados por el Fondo está en este país y una quita sustantiva de los acreedores privados le facilitaría al Fondo la posibilidad de cobrar la deuda con Argentina (Nemiña y Val 2020).

Queda entonces complementar el análisis de la relación contemporánea entre el Fondo y Argentina a partir de las Misiones desde la teoría de los Campos de Bourdieu, y así, dilucidarlas implicancias de esta relación.

\section{El FMI en Argentina}

\section{IV.1. Análisis de la Misiones 2002-2006}

El propio jefe del Departamento para América Latina del Fondo Monetario Internacional, Anoop Singh, encabezó la misión que llegó a la Argentina a principios de 2002. Su primera aparición pública, que fue calificada en la tapa de los periódicos como inusual, consistió en una 
conferencia de prensa que según los testigos pareció improvisada, pero que fue preparada con antelación por el vocero del organismo para la región (Zaiat 2002). Se llevó a cabo en las mismas dependencias del Ministerio de Economía, sin la presencia del ministro, al que por otra parte le quedaban pocos días en el cargo, ni de ninguna otra autoridad local. El representante del Fondo, en la escena la única voz oficial, advirtió que al país sólo le esperaba un camino penoso si intentaba salir de la crisis sin la ayuda de la comunidad internacional, al que, según él, el Fondo representaba. Posteriormente, leyó una declaración donde expresaba las duras condiciones de la nueva negociación que se iniciaba. Las que hizo públicas en ese momento fueron la eliminación del déficit y los bonos de las provincias, el control de la inflación y los cambios en las leyes de Quiebras y de Subversión Económica. Estas dos leyes se habían transformado, por su reactualización judicial, en una importante amenaza al patrimonio de las empresas y de los bancos, así como a la libertad personal de sus gerentes.

Para contar con el favor de su visita al país, en realidad el Fondo ya había impuesto una condición previa, sin la cual no se llevaría a cabo ninguna negociación: la modificación de régimen cambiario adoptado en la reciente salida de la convertibilidad, que contaba con algunos controles establecidos hacía algunas semanas sobre el tipo de cambio, para dar lugar a una flotación libre del dólar. El aumento de su precio y una fuerte aceleración de la inflación fueron sus consecuencias lógicas, que agravaban aún más las de por sí difíciles circunstancias económicas de un país que atravesaba una profunda crisis política y social, resultado de una sucesión de medidas económicas llevadas a cabo durante una década con el aval explícito del mismo organismo internacional, cuyo conspicuo representante dejaba asentado sus requerimientos al gobierno nacional desde sus mismos salones oficiales. Era el principio de una larga negociación que no culminaría hasta el año siguiente (Labaqui 2011).

El Fondo presionaba para que las escasas reservas del Banco Central no se utilizaran para la contención de la demanda de dólares y fueran destinadas para el cumplimiento de las deudas con los organismos internacionales que sumaban más de U\$S 9.500 millones (las dos terceras partes con el propio FMI) y que, justamente, eran la causa de la pérdida de la mitad de la disponibilidad de divisas de la institución en la primera parte de ese año. Las condiciones que imponía el Fondo debían ser cumplidas en un contexto 
de derrumbe de todos los indicadores económicos y sociales, que pueden sintetizarse señalando la caída de casi el $11 \%$ de PBI, una pobreza de casi el 50\% y un desempleo de más del 20\%, tal como lo informó el INDEC en mayo de ese 2002 (Rapoport 2010).

Pero era la propia situación del gobierno la que sumaba aún más interrogantes a la cuestión. Surgido por el voto en asamblea parlamentaria, no contaba con la legitimidad que sólo puede dar el sufragio universal, en un clima de descontento social generalizado, cuyas manifestaciones cotidianas eran protagonizadas por movimientos sociales, piqueteros y ahorristas que reclamaban por sus depósitos bancarios en dólares (Schilfman 2005).

A la luz de los acontecimientos posteriores, puede resultar un tanto ingenua la pretensión del gobierno, al principio de las negociaciones, de obtener un préstamo de U\$s20.000 millones por parte del FMI, cuyo staff mostró desde el principio una posición extremadamente dura. El nuevo ministro de economía, Roberto Lavagna, obtuvo una reprogramación de vencimientos de algo menos de U\$S 1.000 millones, pero sólo a cambio del ajuste fiscal en las provincias y la derogación de las Leyes de Quiebras y de Subversión económica (Brenta y Rapoport 2003).

A mediados de 2002, la negociación parecía estar en su punto más crítico y el necesario aval del FMI parecía muy lejano. Es en ese punto donde aparece el gobierno de los EE.UU. con la propuesta de crear una comisión de notables, compuesta fundamentalmente por ex presidentes de Bancos Centrales europeos, que de manera imparcial analizaría la situación. Fue esta intervención la que favoreció la posición argentina frente a la intransigencia del staff del FMI, ya que esa comisión ad hoc respaldó las razones del prestatario. A esta noticia favorable se sumaba cierto mejoramiento de la economía en el tercer trimestre, pero el optimismo tenía un límite concreto. Antes de fin de año, vencían prestamos, dadas las circunstancias de difícil cumplimiento, con el propio organismo y otro con el Banco Mundial por un total de U\$s.3500 millones. Nuevamente, aparecieron países centrales y potencias extranjeras con importantes intereses empresarios en el país (España, Francia y por supuesto EE.UU.) para obtener una postergación. La Argentina sólo realizó un pago simbólico de casi U\$s80 millones al Banco Mundial. No obstante, el staff siguió adelante con las demandas: mayor ajuste fiscal para el año 2003, liberación 
de controles en el mercado de cambios, la implementación de un canje compulsivo por bonos de depósitos reprogramados y aumento de las tarifas de servicios públicos (Rapoport 2010).

El año 2003 comenzaba con nuevos vencimientos con los dos organismos. El gobierno argentino comprendió definitivamente que la solución no estaba en la discusión técnica con la misión del Fondo. Una oportuna gira del ministro Lavagna por Europa garantizó el apoyo del G7. Mientras el staff alertaba sobre los posibles incumplimientos de Argentina, contrariamente a esta posición, el Directorio del organismo dio inicio a lo que llamó un "Programa de Transición". Consistía en un acuerdo stand-by de corto plazo que no proveía fondos frescos, sino que sólo otorgaba financiamiento para hacer frente a los pagos a organismos multilaterales.

Una Argentina arrasada por la grave crisis económica y social constituía un desafío extraordinario para una elite política sumida en uno de los niveles más bajos de legitimidad que se recuerden. La urgencia económicofinanciera era tan acuciante como el escaso margen de gobernabilidad con que contaba el gobierno asumido en enero de 2002. La lectura que hicieron sus representantes fue que la falta de divisas para cumplir con las obligaciones sólo podría provenir de los organismos multilaterales de crédito, lo que ayudaría a su vez a tranquilizar la endeble situación política. Recurrir al Fondo, no sólo era un camino de obtención de un nuevo préstamo, era también una declaración inequívoca de la voluntad de seguir ocupando una posición dentro del campo internacional. Coincidía en esta cuestión crucial el representante del organismo cuando advertía, al inicio de las negociaciones, en el convulsionado marzo de 2002, sobre el camino penoso que le esperaba al país si buscaba alternativas por fuera de la "comunidad internacional" y, fundamentalmente, por fuera de la institución multilateral, cuya burocracia siempre se encuentra ávida de legitimar su necesidad. En definitiva, una sencilla apelación al "universalismo" que siempre aparece como fundamento último de las políticas asociadas a la desregulación de los mercados y al resto de las prescripciones tan bien sintetizadas en el "consenso de Washington". La "salida de la crisis" no acepta la salida del campo internacional, con sus duras reglas del juego, como la repetida política de ajuste, siempre al servicio de los dominantes. Desconocer al Fondo implica que el resto de los actores del campo financiero desconozcan la tregua, esto es la renegociación de deuda y 
nuevos créditos, lo que abre la posibilidad de someterse a juicios internacionales y embargos, entre otras consecuencias. Esto indudablemente mellaría el poder simbólico del Estado-nación en el campo internacional y por lo tanto en el campo nacional. En este sentido, el duro ajuste es parte del costo para acceder a la gobernabilidad.

En este sentido, el FMI opera como una elite financiera que se eleva sobre los estados nacionales, presentándose como un poder extraterritorial librado de toda atadura o interés nacional, pero que cuenta con la supervisión del más fuerte de ellos, Estados Unidos.

Un acuerdo con el FMI es algo más que equilibrios de balance de pagos, ajustes estructurales y, en el mejor de los casos, fondos frescos para equilibrar el tipo de cambio. Un acuerdo otorga también, por medio de las disposiciones adquiridas, el reconocimiento del lugar de uno en el juego de relaciones y el reconocimiento de la posición que ocupan los dominantes. Los viajes a Washington que suelen emprender los ministros de economía, encierran tanto el aspecto simbólico del reconocimiento del poder, como la ratificación espacial de la ciudad en su carácter de doble sede. Por un lado, es el lugar geográfico de la institución internacional y, por el otro, capital del Estado Nación más poderoso. Reconocimiento de un poder cuya fuerza principal es la creencia en su propia evidencia. En ese espacio de relaciones de fuerza, la posición dominante en el campo es conocida y reconocida por el resto de los agentes que, ya sea con entusiasmo o resignación, recurren a la legitimidad que puede otorgar seguir jugando el juego que, con todas sus penurias, es preferible a la sanción o, lo más grave, la expulsión. Las elites políticas de la historia argentina que se encuentran acuciadas por el corto plazo del juego democrático, buscan soluciones de corto plazo para una economía que hasta entonces ha estado marcada a fuego por los ciclos de stop and go, compatible con la lógica cortoplacista del campo financiero internacional.

En septiembre de 2003, se suscribió un acuerdo de tres años encaminado a refinanciar aquellos vencimientos de capital con el organismo, sujetos a los términos habituales de condicionalidad para el primer año. Los de los dos años siguientes quedaron atados a negociaciones posteriores. La más importante de las metas comprometidas era la magnitud del superávit fiscal primario consolidado. Otras metas importantes incluidas en el acuerdo eran la redefinición de los contratos de concesión y el establecimiento de nuevas 
regulaciones de las tarifas públicas de las empresas privatizadas, la introducción de medidas tendientes a fortalecer el sistema financiero y la aprobación de una ley de distribución de recursos fiscales entre la Nación y las provincias. La condicionalidad incluyó también una cláusula bajo la cual el país se comprometía a un tratamiento de "buena fe". En definitiva, significaba el reconocimiento del FMI como acreedor privilegiado que no sufriría quita alguna. Dos semanas después, el país se encontraba presentando públicamente la propuesta de reestructuración de la deuda y organizando el canje con acreedores privados. Para alcanzar finalmente una quita de casi el 60\% del stock total de deuda (Val 2018).

En ese momento, la Argentina resolvió suspender el acuerdo hasta principios de 2005. A partir de ahí, además de los intereses, la Argentina pagó puntillosamente los vencimientos de capital. En el periodo 2002-2004 el país efectuó pagos netos de capital al FMI por más de U\$S 2.100 millones, junto con unos U\$S 1.900 millones adicionales en concepto de intereses. El broche final a esta serie de desembolsos fue la decisión del gobierno argentino de cancelar por completo la deuda con el organismo en enero de 2006, comprometiendo más de la tercera parte de las reservas líquidas. El pago rondó los U\$s 10.000 millones (casi el 10\% de la deuda pública argentina). Con esa decisión se puso fin a la misión del Fondo en la Argentina. Habría que esperar 10 años para la reactivación del Art. IV.

\section{IV.2. Argentina-FMI. Misión 2016-2018}

En el año 2016, la relación entre Argentina y el FMI volvió a estrecharse a partir de un progresivo reconocimiento mutuo. En enero de ese año, el gobierno fue el primero en dar ese paso al anunciar en el Foro económico de Davos que reactivaría el Art. IV, lo que implicaba la vuelta de las Misiones del Fondo a la Argentina (Infobae, 22 de enero de 2016). Tras este gesto, en el mes de febrero, el FMI hizo lo propio al publicar los informes reservados que el Organismo había realizado sobre Argentina desde el año 2013 (Sticco 2016). Por un lado, esto demostraba que pese a la "conflictiva" relación que el Organismo había mantenido con el gobierno anterior, había continuado monitoreando la economía argentina, dando cuenta de su intención de perpetuar la rutina de la dependencia. Por otro lado, la publicación de aquellos informes a tan solo dos meses de gobierno, 
manifiesta una suerte de declaración de confianza del Fondo a la nueva elite gobernante y una ruptura explícita respecto al gobierno anterior.

En el mes de abril, el gobierno argentino acordó el pago a los "Fondos buitres"7, lo que contribuía a redimirse frente al capital financiero internacional, abriendo camino hacia un nuevo periodo de endeudamiento (Mars 2016). El gobierno así presentaba su "ficha limpia" antes de recibir la primera Misión del Fondo en más de una década, que sucedió finalmente en septiembre de 2016. En el informe final, se incluyeron los primeros elogios, en lo que iba del siglo, de una misión del Organismo hacia un gobierno argentino. En este intercambio de gestos de aprobación, una vez más, el Fondo continuó legitimando al gobierno local al remover la moción de censura que había aplicado en febrero del 2013 por falta de fiabilidad en el INDEC (FMI 2016). Después de haber desconfiado durante años de las estadísticas argentinas, estas breves e intensas visitas resultaron suficientes para que el FMI vuelva a legitimarlas.

Tal como lo estipula el Art IV, al año siguiente volvieron a la Argentina los funcionarios del Fondo. Esta vez el keymessage contaba con más prescripciones que elogios. Se reclamaban reformas estructurales en línea con los requerimientos clásicos de la institución: reducción del gasto público, en particular lo referido a los salarios, las pensiones y las transferencias sociales, cese de supuestas barreras al comercio y a la inversión, reducción de impuestos a las importaciones, ampliación del mercado de capitales, entre sus puntos centrales (FMI 2017). Una vez más, el Fondo propiciaba el ajuste. Mientras tanto, el gobierno aprovechaba el buen visto del Organismo y contraía deuda en el mercado financiero. A tan solo dos años de gobierno, la deuda externa bruta aumentó un 47\% pasando de U\$S 157.792 millones a finales del 2015 a U\$S 232.952 millones a finales del 2017, en lo que se incluye la colocación de deuda a 100 años (Ámbito 2020). En ese entonces, el campo financiero internacional celebraba la política de endeudamiento argentino. El riesgo país, que mide

\footnotetext{
${ }^{7}$ Por fondos buitres entendemos a los fondos de capital riesgo o fondos de inversión libre que invierte en una deuda pública de una entidad que se considera cercana a la quiebra. Los fondos buitre compran en el mercado deuda de Estados y empresas al borde de la quiebra, a un porcentaje muy inferior al de su valor nominal para luego litigar judicialmente o presionar por el pago del $100 \%$ de ese valor.
} 
la probabilidad de incumplimiento de las obligaciones financieras de una nación, y que, por lo tanto, es utilizado como guía por los agentes financieros, alcanzaba los 360 puntos, resultado que apenas fue superado en el 2006 tras la reestructuración de la deuda privada y el pago por adelantado al FMI (Invenómica 2020). La euforia generalizada en los mercados durante el masivo endeudamiento durante el 2017 no contaba con un solo indicio que demuestre que el país estaría en condiciones de poder devolver la deuda, pero si con el aval del Fondo (NdA 2017).

La visita más trascendente del Fondo fue la que hizo en marzo de 2018 la propia presidenta del Organismo, que mantuvo publicitadas y sugestivas reuniones con el presidente de la Nación. Dos meses después éste proclamó el pedido de ayuda financiera al FMI (FMI 2018). En junio se anunció oficialmente el acuerdo stand by, en medio de unas semanas de corrida cambiaria, con la consecuente pérdida de reservas del BCRA, tasas de interés récord y una fuerte devaluación del $50 \%$ en un año de la moneda local. Ese anuncio se llevó a cabo en el Centro Cultural Kirchner. Pocos se percataron de que el lugar del evento llevaba el nombre del presidente que había cancelado la deuda con el Fondo 12 años antes. El préstamo constaba de un monto histórico de U\$S 50.000 (ampliado en U\$S 7000 millones más, poco después), equivalente al $80 \%$ del total de préstamos del Organismo, con 36 meses de plazo que se comenzaría a pagar en 2021. De la suma total, el 30\% fue desembolsado el 20 de junio. En ese momento, se confirmó que el Fondo instalaría una oficina en el Banco Central para monitorear más de cerca el acuerdo con Argentina (Wende 2018).

El inusitado tamaño del rescate financiero contaba con la reticencia del propio staff y de la parte europea del Directorio del Organismo. En ese mismo momento, ya se hablaba de un apoyo político de los EEUU como explicación del intento de salvar una situación económica profundamente crítica de muy difícil resolución (Ahmann 2018; El Comercio 2018). Las intenciones de Estados Unidos de garantizar la continuidad del ciclo político del macrismo no solo permitían aislar aún más al ex aliado Venezuela, sino que también servía para romper con la alianza geopolítica que Argentina había privilegiado unos años antes con Rusia y China (Lejtman 2020). Esto explica la presión política de los Estados Unidos por sancionar el acuerdo, pese a la inicial resistencia de los países europeos. Las razones técnicas del mismo parecían contradecir las políticas, pero las primeras carecían a su vez 
de razonabilidad en sí mismas, a menos que alguien pudiera concebir que la Argentina tuviera alguna posibilidad razonable de responder al cronograma de pagos del acuerdo. El monto desembolsado finalmente por el Fondo fue de U\$S 45.000 millones, una cifra similar a lo que el país debería devolver entre 2022-2023, lo que hubiese significado que la Argentina comprometía algo así como el 5\% del PBI estimado para cada uno de esos años, solo con el organismo, sin tomar en cuenta el cronograma de pagos por bonos. La imposibilidad totalmente a las claras, incluso para el análisis menos experto, de cumplir con los términos acordados, abría en sí misma, la probable refinanciación posterior de esa deuda. Se trataba entonces de posponer una crisis. Además, es para situaciones como esta que existen los Funds Extended Facilities (EFF) que si bien aporta fondos usualmente menores a los stand-by lo hace por un tiempo más prolongado (cuatro años) y con mayor plazo de repago (hasta diez años después de concretado el desembolso). Las facilidades extendidas están supeditadas al cumplimiento de criterios cuantitativos, como son las metas fiscales, pero también a la aplicación de ciertas políticas estructurales que contribuyan a estabilizar la macroeconomía, aunque menos exigentes en lo fiscal que los stand-by.

Pero hay un elemento que llamó la atención de los analistas, además de que el préstamo fuera el más grande en la historia del FMI. La propia normativa del organismo establece que los desembolsos anuales no pueden superar el $145 \%$ de la cuota del país miembro en cada uno de los tres años de duración del acuerdo. Pero resulta ser que el préstamo stand-by solicitado por la Argentina fue un acuerdo de "acceso excepcional" cuyo monto equivale aproximadamente al $1.270 \%$ de la cuota que paga para formar parte del FMI. Este descuido hacia la propia normativa burocrática refleja el peso de las razones políticas más allá de los criterios técnicos del staff.

Luego de un hiato de 10 años, la reactivación de las Misiones con el Fondo parecía haber dado sus frutos, tras celebrar un nuevo Acuerdo. La "vuelta al Fondo", como se la proclamó desde posiciones oficiales y opositoras, significó la reactualización de una rutina ya bien aprendida y nunca del todo olvidada. En el marco de sus ciclos económicos repetitivos con sus concomitantes crisis recurrentes y el inveterado proceso de endeudamiento, las elites políticas reactualizan sus disposiciones adquiridas temerosas de la siempre amenazante pérdida de gobernabilidad. La experiencia histórica sobre las graves consecuencias políticas que conllevan 
las recursivas crisis económicas promueve la búsqueda de una legitimidad externa que apuntale, al menos en parte, la averiada credibilidad interna. Toda fuente de legitimidad política parece reducirse a las señales diarias que ofrece el tipo de cambio, cuya cotización no siempre es sensible a la acción de los tímidos instrumentos de control. Es en esas condiciones en que el Fondo aparece no sólo como un prestamista de última instancia de dólares frescos que estabilizan reservas líquidas menguantes, también se constituye como un prestamista de legitimidad de última instancia en la búsqueda de romper con el circuito de pérdida de reservas, pérdida de estabilidad económica, pérdida de credibilidad, pérdida de gobernabilidad.

Puede pensarse al Fondo como algo más que su staff de técnicos de impecable presencia que arriban en las "Misiones", cuenta también con el poder simbólico de sus "señales", sus diagnósticos, sus recomendaciones y sus exigencias, y, de ser necesario, cuenta con la última instancia de la última instancia, que se materializa cabalmente en la distribución asimétrica de su Directorio. Los siempre discutibles resultados económicos, por no hablar de los sociales, de los créditos stand-by, con sus consecuencias de ajustes recurrentes y pagos de intereses incumplibles son el precio elevado que pagan elites políticas de autoridad débil a cambio de las "señales" que calmen a "los mercados" para recuperar una "confianza" que no conoce de plazos largos. Por más alto que sea el costo a pagar, nunca lo será tanto como la amenaza de perder la posición, por poco relevante que fuere, dentro del campo internacional. Las Misiones del Fondo expresan esa garantía y reafirman la pertenencia al campo y el reconocimiento del poder simbólico de aquellos que lo dominan.

\section{Conclusión}

Este artículo comenzó indagando en los aspectos políticos y simbólicos de la relación entre Argentina y el FMI, e hizo hincapié en que la presencia del Fondo durante las Misiones de 2002-2006 y 2016-2018, en un Estado frágil como el argentino, le ha otorgado al sistema político gobernabilidad a través de su capital simbólico.

Por un lado, la presencia del FMI durante las Misiones permitió comprender la interacción cotidiana, por fuera de los Acuerdos recurrentes. 
Estas poseen un carácter rutinario en términos espaciales y temporales. Durante ambas Misiones, el Fondo dispuso periódicamente de las oficinas públicas, llevó a cabo enunciados conjuntos o independientes de la elite gobernante, señaló las medidas que el Estado debía adoptar, y finalmente aprobó o desaprobó el cumplimiento de aquellas disposiciones. Esta rutina de la dependencia, en términos de Kedar, a la que la elite local somete al Estado es el costo que debe pagar para acceder a la gobernabilidad, y le permite al FMI compartir junto al Estado el monopolio de la violencia simbólica, sin perder su carácter de instancia supraestatal.

La elite gobernante no tuvo otra alternativa que someterse a esta relación porque reconoce al campo financiero internacional como la solución, por lo menos momentánea, a la incapacidad de su sistema productivo para obtener divisas y así sustentar el equilibrio macroeconómico. En este sentido, el campo financiero internacional es tácitamente convenido como una fuente de capital necesario para legitimar a un gobierno económicamente, y (por lo tanto) políticamente débil. Se trata entonces, de un sometimiento que es consensuado y necesario. Desde la perspectiva del resto de los acreedores externos del que el Estado es deudor, la gobernabilidad otorgada por la presencia del Fondo es la instancia que garantiza el repago de la deuda.

Durante las Misiones iniciadas en el 2002, la debilidad para gobernar respondió a la crisis económica de 2001, que también generó una crisis institucional y política sin precedentes. Esta había sido el resultado de una década de reformas en las que el Fondo había sido uno de los principales promotores. El gobierno resultante de esta crisis, que ni siquiera tenía representatividad otorgada por el voto popular y que tenía que afrontar una deuda impagable, necesitaba de la legitimidad que el Fondo podía concederle frente al mercado externo. Estaba claro que los acreedores privados no confiarían en el Estado Argentino (al menos por un tiempo) y que su intermediación se tornaba necesaria.

En las Misiones que se inician a partir del año 2016, la situación económica y política probablemente fue menos extrema, pero las disposiciones fueron las mismas. Por un lado, la elite contaba con el apoyo del sufragio universal, aunque la diferencia con respecto al partido opositor mayoritario era mínima. Por otra parte, la elite local no podía lanzarse sobre el mercado de crédito externo para financiar sus desequilibrios sin antes tener la legitimidad del Fondo. Para eso, se necesitaba retomar las Misiones 
que habían quedado suspendidas durante 10 años. Tras el masivo endeudamiento privado a partir de 2016, el crédito externo comenzó a contraerse, hecho que cuestionó la viabilidad económica de la Argentina, y una vez más, el Fondo, no solo sirvió para coyunturalmente financiar los desequilibrios a partir de una suma inédita, sino también y, sobre todo, para legitimar una política económica local que había entrado en cuestionamiento. La disposición de capital simbólico le permitió al gobierno argentino replantear el devenir de los vencimientos y posponer pagos como medio para lograr viabilidad política.

En este sentido, se comprueba que en los dos escenarios la relación con el Fondo garantiza no solo recursos frescos, sino también una valoración positiva en términos de legitimidad. El Fondo, en tanto poseedor de capital económico y simbólico se presenta como la primera instancia para acceder al crédito externo (tanto durante los noventa como durante el 2016 y 2017), y como la última instancia para salir de las crisis de crédito externo. Es la puerta de entrada al campo financiero y su puerta de salida en situaciones de crisis. Una dependencia rutinaria.

Cuando está en peligro la gobernabilidad, lo que entre otras cosas pone en riesgo la devolución de la deuda, el Fondo otorga un paliativo económico que siempre es acompañado de algo más; de su capital simbólico, que implica un interregno generalizado del mercado financiero que le permite a la elite política reorganizarse para, en el mejor de los casos, pagar la deuda o, como sucede generalmente, simplemente posponerla. El Acuerdo del 2018 es el claro ejemplo de esta última opción. Argentina no tenía ninguna posibilidad de pagar su deuda con el Fondo en los términos fijados. Sin embargo, permitía dilatar el plazo para la próxima crisis.

En contexto de crisis económica, la elite política no tiene otra alternativa que acceder al capital simbólico que le ofrece "la última instancia". En todos los casos es reconocido como la solución; ya sea que permite saltear por un tiempo del hostigamiento del resto de los actores financieros y acceder a una quita de la deuda, solventar el endeudamiento inconsistente del gobierno local o incluso también aparecer como la solución frente a los errores del propio Fondo en su carácter de primera instancia. La evidencia más gráfica puede verse en la frase acuñada por el Ministro de Economía Remes Lenicov quien declaró en febrero del 2002 "todos los caminos conducen al FMI", a solo dos meses de la declaración de default, en la peor crisis social, 
económica y política de la historia argentina. Si bien el Fondo había sido el promotor de las reformas y políticas económicas durante los 90, y por lo tanto había sido el problema, ya no importaba, lo que si estaba claro es que en esa instancia de crisis era parte de la solución.

En la economía argentina, caracterizada por las mencionadas crisis recurrentes producto de su estructura productiva ineficiente, desconocer al Fondo resultaría inviable porque desconocer el campo financiero internacional sería prescindir de una de las principales fuentes de legitimidad para mantener la gobernabilidad. Por lo tanto, el Estado nación argentino, que atraviesa crisis económicas recurrentes, construye la base de la confianza del mercado financiero y de la comunidad internacional a partir de su relación con el FMI.

Por último, la descripción de ambos periodos de las Misiones también ha servido para demostrar que la voluntad política de los Estados Unidos es decisiva para la implementación de los acuerdos posteriores, incluso cuando esto se opone a las manifestaciones "técnicas" de la burocracia. Durante la misión que va de 2002 al 2006, el staff del Fondo mantuvo una actitud confrontativa con la elite política, oponiéndose a cualquier solicitud local, pero fue Estados Unidos quien destrabó las negociaciones del FMI con Argentina que encontraban a una burocracia mucho más reticente tras la suspensión del acuerdo en el 2001. Durante las Misiones iniciadas en el 2016, sucedió algo similar: El staff del Fondo y los miembros europeos discrepaban con la idea de implementar un inédito Acuerdo, pero fue el apoyo de EEUU que permitió celebrar un programa récord en cuanto a la cifra económica. En este sentido, el análisis de las Misiones permite también reconocer al agente dominante principal, interesado en que nadie se salga de juego.

\section{Referencias}

Ahmann, Tim. 4 de septiembre de 2018. "Trump says U.S. supports Argentina, backs its efforts with IMF'. Reuters, emerging markets. Recuperado de: https://www.reuters.com/article/us-argentina-economytrump-idUSKCN1LK270 
Bellini, Claudio, y Juan C. Korol. 2012. Historia económica de la Argentina en el siglo $X X$. Buenos Aires: Siglo XX.

Blanchard, Olivier, Giovanni Dell'Ariccia y Paolo Mauro. 2010. "Rethinking Macroeconomic Policy. IMF Staff Position Note". International Monetary Fund. Research Department. SPN/10/03

Bona, Leandro M. 2019. “¿Neoliberalismo hegemónico? Apuntes sobre el Estado, el bloque de poder y la economía política en la Argentina reciente (2016-2018)". Revista Pilquen. Sección Ciencias Sociales 22 (1): 39-54. Bonavida, Cristian, Paola Gevaerd Bernal, Lautaro González Obregón, Bernardo Dikstein, Javier Kutnich, Hugo Velazquez, y Pablo Nemiña. 2018. "Argentina y el FMI: análisis de un nuevo acuerdo". Chaco. Escuela de Gobierno. Recuperado de:

http://www.escueladegobierno.chaco.gov.ar/files/documentos-detrabajo/informe-endeudamiento-fmi.pdf

Bourdieu, Pierre. 1997. "La esencia del neoliberalismo". Revista Colombiana de educación 35. . 2003. "Algunas propiedades de los campos". En Campo de Poder, Campo Intelectual. Itinerario de un Concepto. Buenos Aires: Quadrata. Bourdieu, Pierre, y Jean Claude Passeron. 2001. "Fundamentos de una teoría de la violencia simbólica”. En La reproducción. Elementos para una teoría del sistema de enseñanza, págs. 13-85.

Brenta, Noemí. 2004. "Las propuestas de dolarización en América Latina: rol del FMI, EE. UU. y los thinktanks en los años' 90”. Ciclos en la historia, la economía y la sociedad 14 (27): 17-48.

2011. "Argentina y el FMI: efectos económicos de los programas de ajuste de larga duración". Anuario del Centro de Estudios Históricos Profesor Carlos S. A. Segreti 11: 17-39.

Brenta, Noemí y Mario Rapoport. 2003.” El FMI y la Argentina en los años '90: de la hiperinflación a la hiperdesocupación'. En Los guardianes del dinero: las políticas del FMI en la Argentina, coordinado por N. Mingsburg e I. Antognazzi, págs. 27-46. Buenos Aires: Norma.

Camou, Antonio. 2000. "La múltiple (in) gobernabilidad: elementos para un análisis conceptual”. Revista mexicana de sociología 62 (4): 159-188.

Chwieroth, Jeffrey M. 2015. "Professional ties that bind: how normative orientations shape IMF conditionality". Review of International Political Economy 22 (4): 757-787. 
Cuattromo, Juan. 2018. "Las consecuencias del ajuste según el FMI". BORDES 10: 29-37.

Edwards, Martin S. y S. Senger. 2015. "Listening to advice: Assessing the external impact of IMF article IV consultations of the united states, 20102011”. International Studies Perspective 16 (3): 312-326.

doi: 10.1111/insp.12059

El Comercio. 2018. "Donald Trump expresa el 'firme apoyo' de EE.UU. a Argentina”. Suplemento Actualidad (4 de septiembre). Recuperado de: https://www.elcomercio.com/actualidad/donaldtrump-eeuu-firmeapoyo-argentina.html

Fondo Monetario International. 2011. Convenio Constitutivo del Fondo Monetario Internacional. Washington D.C. Recuperado de: https://www.imf.org/external/spanish/pubs/ft/aa/aa.pdf

_ 2016. "IMF Executive Board Removes Declaration of Censure on Argentina. PRESS RELEASE NO. 16/497” (9 de noviembre). https://www.imf.org/en/News/Articles/2016/11/09/PR16497-

Argentina-IMF-Executive-Board-Removes-Declaration-of-Censure

_ 2017. "El personal técnico del FMI concluye la misión del Artículo IV con Argentina correspondiente a 2017. COMUNICADO DE PRENSA NO. 17/431" (10 de noviembre). Recuperado de: https://www.imf.org/es/News/Articles/2017/11/10/pr17431-imf-staffcompletes-2017-article-iv-mission-to-argentina

-2018. "El Directorio Ejecutivo del FMI aprueba un Acuerdo StandBy por USD 50.000 millones para Argentina. COMUNICADO DE PRENSA NO. 18/245" (20 de junio). Recuperado de: https://www.imf.org/es/News/Articles/2018/06/20/pr18245-argentinaimf-executive-board-approves-us50-billion-stand-by-arrangement Giavedoni, José Gabriel. 2018. "La Revolución Libertadora y el surgimiento de la razón neoliberal”. Realidad Económica 47 (317): 9-40. Girón, Alicia. 2006. "Financiamiento del desarrollo: endeudamiento externo y reformas financieras." En Repensar la teoría del desarrollo en un contexto de globalización. Homenaje a Celso Furtado, edición y distribución cooperativa, págs. 125-142. Buenos Aires: Consejo Latinoamericano de Ciencias Sociales (CLACSO). 
2010. "Democracia, Washington Consensus y FMI en América Latina". En América Latina: Democracia, Economía y Desarrollo Social, págs. 31-42. Madrid: Trama editorial.

INDEC. 2020. "Balanza de pagos, posición de inversión internacional y deuda externa. Primer trimestre de 2020. Cuentas nacionales". INDEC informes técnicos 4 (2). Recuperado de:

https://www.indec.gob.ar/uploads/informesdeprensa/bal_06_2045AAE 8C4CE.pdf

Infobae. 2016. "Mauricio Macri, sobre el FMI: 'No tenemos nada que ocultar sin por eso perder independencia"” (22 de enero). Recuperado de: https://www.infobae.com/2016/01/22/1784792-mauricio-macri-el-fmino-tenemos-nada-que-ocultar-eso-perder-independencia/

Invenómica. 2020. "Riesgo País EMBI - América Latina - Serie Histórica" (diciembre). Recuperado de:

https://www.invenomica.com.ar/riesgo-pais-embi-america-latina-seriehistorica/

Jiménez, Juan Pablo, y Fernando Lorenzo. 2010. "Los cambios en el FMI y el impacto en su relación con los países de América Latina”. Pensamiento Iberoamericano 6: 255-283.

Kedar, Claudia. 2012. The international monetary fund and Latin America: the Argentine puzzle in context. Temple University Press.

Kentikelenis, Alexander E., y Sarah Babb, S. 2019. "The Making of Neoliberal Globalization: Norm Substitution and the Politics of Clandestine Institutional Change". American Journal of Sociology 124 (6): 1720-1762. https://doi-org.ezproxy.mpifg.de/10.1086/702900

Labaqui, Ignacio. 2011. “¿Negociando sobre la cubierta del Titanic? La Argentina y el FMI durante el gobierno de Eduardo Duhalde". Anuario del Centro de Estudios Históricos Profesor Carlos SA Segreti 11: 63-81. Lejtman, Román. 2020. "Un asesor de Trump reveló por qué ayudaron al gobierno de Macri a acceder a un rescate del Fondo Monetario Internacional". INFOBAE (28 de julio). Recuperado de: https://www.infobae.com/politica/2020/07/28/un-asesor-de-trumprevelo-por-que-ayudaron-al-gobierno-de-macri-a-acceder-a-un-rescatedel-fondo-monetario-internacional/

Lesage, Dries, Peter Debaere, Sacha Dierckx y Mattias Vermeiren. 2013. "IMF reform after the crisis". International Politics 50 (4): 553-578. 
Mars, Amanda. 2016. "Argentina llega a un acuerdo con los fondos buitres tras 14 años de pugna". El Pais (1 de marzo). Recuperado de: https://elpais.com/internacional/2016/02/29/actualidad/1456758816_84 3479.html

Martone, Francesco. 2004. "Sin el fondo ¿quién estará fuera del mundo?: Teoría y práctica de la intervención del FMI en América Latina”. Íconos: revista de ciencias sociales 19: 124-129.

Momani, Bessma. 2010. "Internal or external norm champions: The IMF and multilateral debt relief'. En Owning development: Creating policy norms in the IMF and the world bank, editado por S. Park y A. Vetterlein, págs. 29-47. Cambridge University Press.

Musacchio, Andrés. 2020. "Neoliberalismo, inserción internacional y financiarización: una comparación entre Argentina y Portugal". Problemas del Desarrollo. Revista Latinoamericana de Economía 51 (201).

Natanson, José. 2019. “Argentina: elecciones en tiempos de grieta”. Nueva sociedad 281: 4-11.

NdA. 2017. "Dujovne se reunió con la directoria del Fondo en Davos". Notas de Actualidad (18 de enero). Recuperado de: https://notasdeactualidad.com.ar/dujovne-se-reunio-con-la-directoradel-fmi-en-davos/

Nelson, Stephen C. 2017. The currency of confidence: How economic beliefs shape the IMF's relationship with its borrowers. Cornell University Press.

Nemiña, Pablo. 2011. "Ajuste, crisis y default: el FMI y la Argentina durante la gestión de De la Rúa (1999-2001)”. Anuario del Centro de Estudios Históricos Prof. Carlos S. A. Segreti 11 (11): 41-61. . 2013. "El FMI y la política económica argentina". Instituto de Estudios de América Latina y el Caribe; Observatorio latinoamericano. 12: $150-163$.

Nemiña, Pablo, y Juan Larralde. 2020. "Prestamista, garante y deudor: El FMI en América Latina y el Caribe en la década posterior a la crisis financiera". Sociedade e Cultura 23.

Nemiña, Pablo, y María Emilia Val. 2020. "La reestructuración de la deuda argentina ante la pandemia global”. Análisis Carolina 19. 
Park, Susan y Antje Vetterlein (eds.). 2010. Owning development: creating policy norms in the IMF and the World Bank. Cambridge University Press

Rapoport, Mario. 2008. Historia económica, política y social de la Argentina (1880-2003), 2a ed. Buenos Aires: Emecé Editores.

- 2010. Las políticas económicas de la Argentina: una breve historia.

Schilman, Fernanda L. 2005. Convivir con el capital financiero, corralito y movimiento de ahorristas (Argentina 2001-2004). Universitat Rovirai Virgili.

Sticco, Daniel. 2016. "Economía reveló los informes reservados del FMI de 2013 a 2015 sobre la Argentina". INFOBAE (29 de febrero). Recuperado de: https://www.infobae.com/2016/02/29/1793765-economia-revelolos-informes-reservados-del-fmi-2013-2015-la-argentina/

Val, María Emilia. 2018. "La negociación entre el gobierno argentino y los acreedores privados en torno a la reestructuración de la deuda soberana en default durante el primer canje (2003-2005)". Tesis de Maestría, UNSAM.

Weber, Max. 2009. La ética protestante y el espiritu del capitalismo.

Wende, Pablo. 2018. "El FMI ya tiene oficina en la Argentina: por el momento funcionará en el Banco Central". INFOBAE, Suplemento Economía (15 de octubre). Recuperado de:

https://www.infobae.com/economia/2018/10/15/el-fmi-ya-tieneoficina-en-la-argentina-por-el-momento-funcionara-en-el-bancocentral/

Zaiat, Alfredo. 2002. "La crisis más difícil que haya pasado un país". Página 12 (11 de abril). Recuperado de: https://www.pagina12.com.ar/diario/elpais/1-3874-2002-04-11.html 